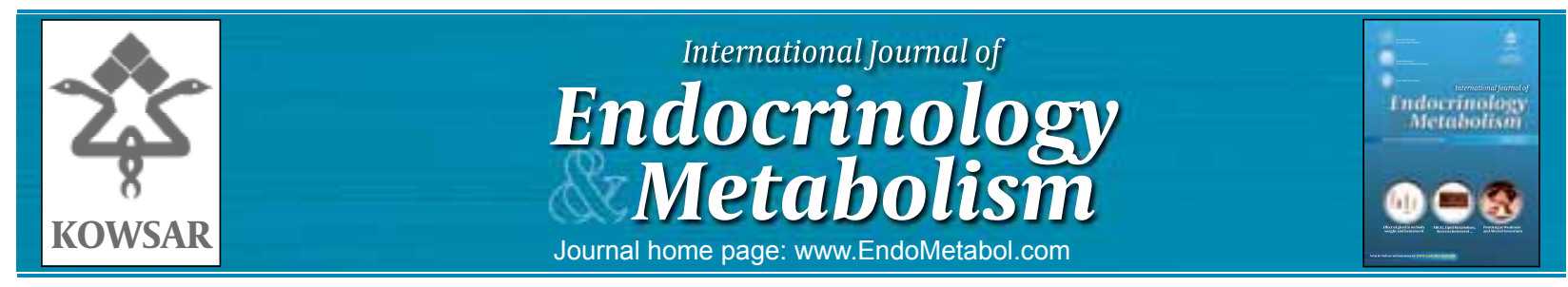

\title{
Pheochromocytoma With Nonspecific Aortoarteritis: an Unusual Association
}

\author{
Sunil Kumar Kota ${ }^{1^{*}}$, Siva Krishna Kota ${ }^{2}$, Prabhas Ranjan Tripathy ${ }^{3}$, Sruti Jammula ${ }^{4}$, Lalit \\ Kumar Meher ${ }^{5}$, Kirtikumar Dharmshibhai Modi ${ }^{1}$ \\ ${ }^{1}$ Department of Endocrinology, Medwin Hospital, Hyderabad, Andhra Pradesh, India \\ 2 Department of Anesthesia, Central Security Hospital, Riyadh, Saudi Arabia \\ ${ }^{3}$ Department of Anatomy, Kalinga Institute of Medical Sciences, Bhubaneswar, Orissa, India \\ ${ }^{4}$ Department of Pharmaceutics, Roland Institute of Pharmaceutical sciences, Berhampur, Orissa, India \\ ${ }^{5}$ Department of medicine, MKCG Medical College, Berhampur, Orissa, India
}

\begin{tabular}{l}
\hline A R T I C L E I N F O \\
\hline Article type: \\
Case Report \\
\hline Article history: \\
Received: 25 Jan 2011 \\
Revised: 20 Mar 2011 \\
Accepted: 03 Apr 2011 \\
\hline
\end{tabular}

Keywords:

Pheochromocytoma

Hypertension

Blood Vessels

\begin{abstract}
A B S T R A C T
Pheochromocytomas have been described to be associated with rare vascular abnormalities, most common of them being renal artery stenosis. A 40-year-old woman was admitted to our hospital with the complaints of headache, sweating, anxiety, dizziness, nausea, vomiting, and severe hypertension. Examination revealed absent carotid and upper-limb pulses with an intact lower-limb pulse. Abdominal computed tomography revealed the presence of a left adrenal pheochromocytoma. An aortogram showed total occlusion of the aortic arch arteries. the Pheochromocytoma was surgically removed, and the patient was then administered steroid treatment for arteritis. To the best of our knowledge, the occurrence of pheochromocytoma along with aortoarteritis has not been reported thus far. The possible mechanisms underlying such an involvement have been discussed in this study.
\end{abstract}

Copyright $\odot 2011$ Kowsar M. P. Co. All rights reserved.

Implication for health policy/practice/research/medical education:

The state of catecholamine excess due to pheochromocytoma can give rise to recurrent vasospasm induced vasculitis and nonspecific aortoarteritis. Adequate and timely attention is required for optimum management of these rarely associated conditions.

- Please cite this paper as:

Kumar Kota S, Krishna Kota S, Tripathy PR, Jammula S, Kumar Meher L, Modi KD, Pheochromocytoma With Nonspecific Aortoarteritis: an Unusual Association. In J Endcrinol Metab. 2011;9(3):416-9. DOI:10.5812/Kowsar.1726913X.2328

\section{Introduction}

Pheochromocytoma is an uncommon cause of hypertension and is estimated to occur in 0.1-1\% of hypertensive patients (1). It can be a potentially lethal disease with protean manifestations. This chromaffin cell tumor secretes catecholamines and other substances (2), either continuously or intermittently, causing sustained or paroxysmal symptoms, respectively. Diagnosis is establi-

* Corresponding author: Sunil Kumar Kota, Department of Endocrinology, Medwin Hospitals, Chiragh Ali Lane, Nampally Hyderabad-500001, Andhra Pradesh, India. Tel: +91-9959369777, Fax: +91-4066623441, E-mail: hidocsunil@ibibo.com

DOI: 10.5812/Kowsar.1726913X.2328

Copyright $\odot 2011$ Kowsar M.P.Co. All rights reserved. shed by measuring the levels of catecholamines or their metabolites in the urine or blood; for example, fractionated catecholamines, fractionated metanephrines, vanillylmandelic acid (VMA) in 24-h urine specimen or plasma metanephrines (3). The tumor is located by performing computed tomography (CT) or magnetic resonance imaging (MRI) (4). Since these tumors recur in some patients even after the removal of the primary tumor (5), followup is essential. Aortoarteritis is a nonspecific inflammatory arteriopathy involving the aorta, its major branches, and sometimes the pulmonary arteries; the arch vessels are also commonly involved. Stenosis and occlusion of the subclavian, carotid, and vertebral arteries together or in various combinations are responsible for the multiplicity of cerebral and visual disturbances (6). Howe- 
ver, there has been no report of any association between aeortoarteritis and pheochromocytoma. We report the case of a woman who presented with pheochromocytoma and nonspecific aortoarteritis.

\section{Case Report}

A 40-year-old woman was admitted to our hospital with complaints of headache, palpitation, sweating, anxiety, breathlessness, dizziness, nausea, and vomiting. She also had constitutional symptoms, including low-grade intermittent fever, loss of appetite, and weight loss over the past 18 months. She did not have a history of pulmonary tuberculosis. She was $164 \mathrm{~cm}$ tall and weighed $57 \mathrm{~kg}$. A hematological analysis showed normochromic anemia, an increased ESR (a 130-mm fall in the first hour, corrected by the hematocrit level calculated by ESR $\times$ hematocrit/45), while the total and differential leucocyte counts were normal. Biochemical parameters such as liver and kidney functions and levels of serum electrolytes, calcium, phosphorous, and alkaline phosphatase were within the normal limits. Electrocardiogram revealed left-ventricular hypertrophy. The chest radiographs and echocardiograms were normal. The endocrinological evaluation included measurement of the levels of catecholamines and assessment of steroids and the renin-angiotensin system. The catecholamines and their metabolites were measured by performing high-performance liquid chromatography-electrochemical detection by using Biorad variant D 10. Automated enzyme immunoassay was used for the assessment of plasma cortisol. Adrenocorticotropic hormone (ACTH), plasmarenin activity, and plasma aldosterone were estimated by radioimmunoassay methods by using the Roche E 601 analyzer. These investigations showed an increase in the levels of urine catecholamines, urinary VMA, and plasma aldosterone and elevated plasma-renin activity (Table 1). The plasma cortisol and ACTH levels were within the normal ranges (Table 1 ).

\begin{tabular}{lll}
\hline \multicolumn{3}{l}{ Table 1. Baseline Biochemical Parameters of the Patient } \\
\hline & Values & Normal Range \\
\hline Plasma rennin activity, ng/mL/h & 7.5 & $0.7-1.4$ \\
Plasma aldosterone, ng/dL & 53.2 & $2-20$ \\
Fractionated metanephrines & 43 & $<1.3$ \\
from 24-h urine, $\mathrm{mg} / 24 \mathrm{~h}$ & & \\
VMA from 24-h urine ${ }^{\mathrm{a}}, \mathrm{mg} / 24 \mathrm{~h}$ & 78 & $1-8$ \\
Plasma metanephrines, $\mu \mathrm{g} / \mathrm{dL}$ & 325 & $<60$ \\
8:00 AM plasma cortisol, $\mu \mathrm{g} / \mathrm{dL}$ & 17.2 & $5-25$ \\
Plasma ACTH ${ }^{\mathrm{a}}, \mathrm{pg} / \mathrm{mL}$ & 23.1 & $10-60$ \\
\hline
\end{tabular}

a Abbreviations: ACTH, Adrenocorticotropic hormone; VMA, Vanillylmandelic acid

Abdominal CT showed a large, heterogenous, para-aortic mass $(5 \times 2 \mathrm{~cm})$ between the celiac and the superior mesenteric artery, with an attenuation score of 35 hounsfield units (HU) (Figure 1). Intra-arterial digital subtrac-

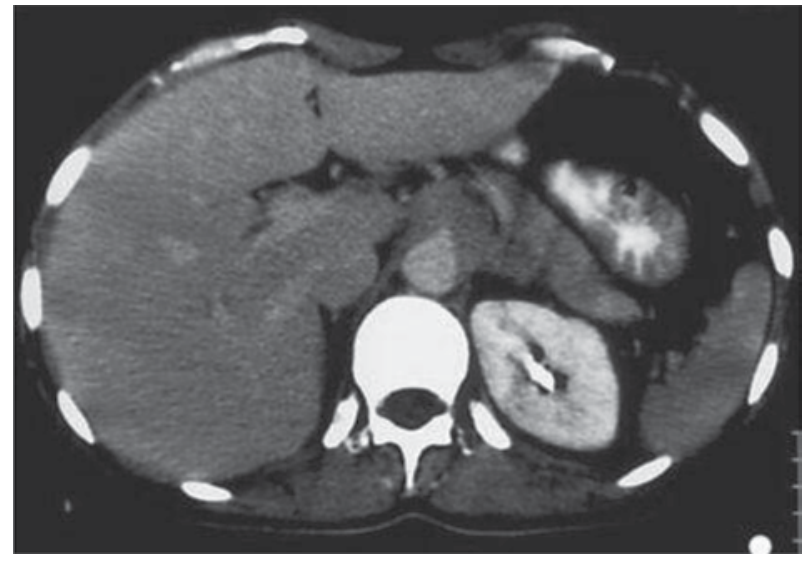

Figure 1. Abdominal Computed Tomography Image Showing a Large, Heterogenous Para-Aortic Mass $(5 \times 2 \mathrm{~cm})$ Between the Celiac Artery and Superior Mesenteric Artery, with an Attenuation Score of 35 Hounsfield Units (HU)

tion angiography was performed on the right femoral artery with the patient under local anesthesia. An arch aortogram revealed total occlusion of both the carotid arteries and both the subclavian arteries (Figure 2).

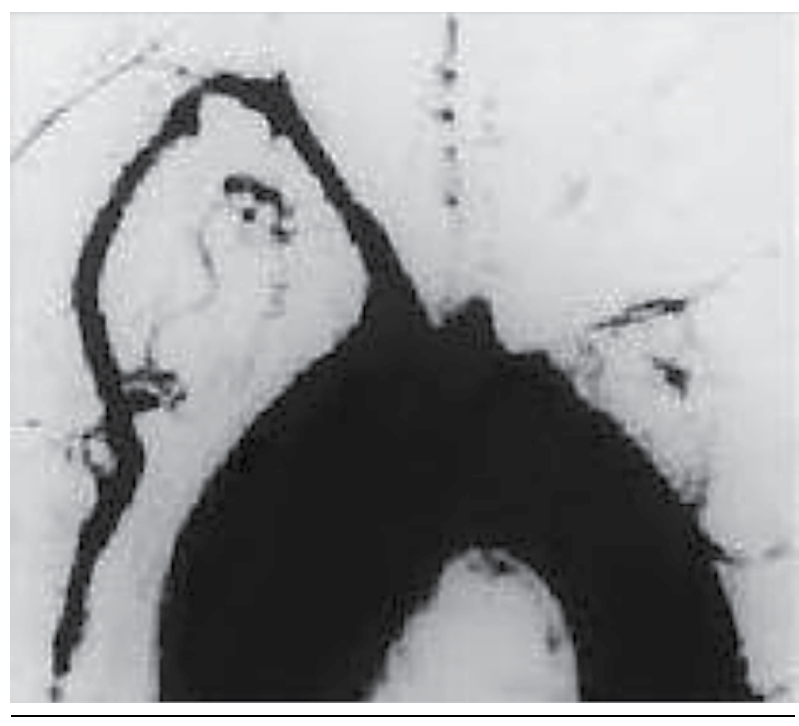

Figure 2. Intra-Arterial Digital Subtraction Angiogram of the Arch of Aorta, Showing Total Occlusion of Both the Common Carotid Arteries and the Subclavian Arteries

An abdominal aortogram showed normal renal arteries and aorta. A pulmonary artery angiogram showed normal pulmonary arteries. We established a diagnosis of Type 1 aortoarteritis with pheochromocytoma and recommended surgical treatment. We initiated therapy with the $\alpha$-receptor blocker prazosin, and after adequate blockade, $\beta$ blockade was done by administering metoprolol. After 2 weeks, hypertension was well under control and the other symptoms disappeared. With adequate blood pressure control, laparoscopic adrenalectomy was performed on the patient. Light microscopy of the specimen showed characteristic organoid or zellballen nest of cells confirming the diagnosis of pheochromocytoma with no cytoplasmic inclusion, pleomorphism, cytologi- 
cal alterations or necrosis; the mitotic index was low (Figure 3). The patient was simultaneously treated with steroids (prednisolone $40 \mathrm{mg}$ daily, in view of clinical activity in the form of fever, weight loss and increased ESR). The steroid dosage was gradually reduced over a period of 4 weeks and maintained at $5 \mathrm{mg} /$ day.

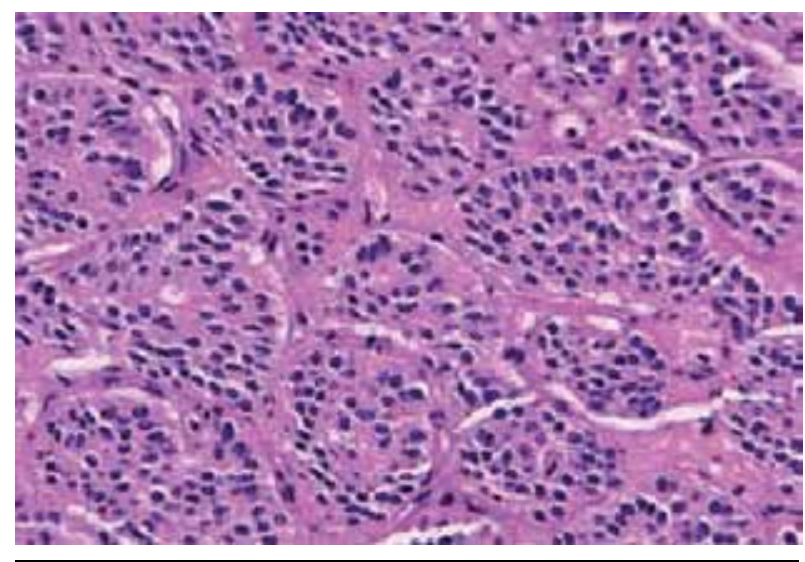

Figure 3. Histology of the Biopsied Specimen Showing Characteristic Organoid or Zellballen Nest of Cells

During the postoperative period, the blood pressure was normal and the patient's convalescence was uncomplicated. She was discharged on the $8^{\text {th }}$ postoperative day. During the next 12 months, the patient's blood pressure remained normal. A 24-h urine sample was collected for analyzing the levels of metanephrines and VMA, which were found to be within the normal ranges. At present, the patient is asymptomatic, requires no medications, and is employed as a teacher. Although her hemoglobin levels improved and ESR reduced, no angiographic improvement was observed.

\section{Discussion}

Two aspects make our case unusual: (i) the coexistence of pheochromocytoma with aortoarteritis in the patient and (ii) possibility that this is the first report citing this uncommon association. The signs and symptoms of Takayasu's arteritis (nonspecific aortoarteritis), a disease with a worldwide distribution and geographic variations, can show considerable clinical variation with regard to severity, duration, and characteristics (7). The onset of the disease is often insidious, and the disease progresses at a variable rate from the active inflammatory phase to the chronic sclerotic phase with intimal hyperplasia, medial degeneration, and adventitial fibrosis (8). Stenotic lesions are more common in these patients than aneurysms (9). The narrowing starts near the orifice of the artery and extends for a variable distance; progressive narrowing leads to occlusion with ischemic symptoms. In such an extreme form of brachiocephalic arteritis, all or most of the arch vessels are occluded and the entire circulation to the brain occurs through the collateral vessels. Our patient did not show any of these symptoms.
The simultaneous occurrence of pheochromocytoma and aortoarteritis, to the best of our knowledge has not yet been described in the literature. In our patient, aortoarteritis could have occurred because (i) persistently high levels of circulating catecholamines may damage the vascular endothelium, resulting in intimal fibrosis in large and medium vessels, which in turn leads to aortoarteritis and (ii) the association of pheochromocytoma with systemic lupus erythematosus and Behcet's disease might explain the triggering of an autoimmune phenomenon leading to aortoarteritis. However, an immunological study on 50 Indian patients with aortoarteritis did not show any involvement of an autoimmune mechanism in aortoarteritis (10) and (3) a chance association between these 2 conditions. The hyperreninemic hyperaldosteronism in our patient could have been induced by uncontrolled hypertension.

Glucocorticoids effectively suppress systemic symptoms and usually arrest the progression of Takayasu's arteritis. The severity of normochromic anemia reduces, and the levels of acute-phase reactants also return to normal (11). In our patient, we noticed improvement in anemia and ESR after the treatment with steroids. Arterial stenosis may be reversed and ischemic symptoms may improve in the early stages. However, the vascular response is diminished once fibrous tissues are formed in the involved vessels or when thrombosis occurs. While some studies have reported angiographic improvements after long-term administration of steroids, we did not observe any such improvements (12). CT or MRI can also be performed to assess the response to therapy (13). No improvement of arterial obstruction has been reported in other studies (14). Kerr et al (9) reported a relapse in half the number of patients, who had initially achieved remission on the administration of steroids. Rapidly increasing aneurysmal size (more than $1 \mathrm{~cm} /$ year) has been reported, despite glucocorticoid therapy (13). Percutaneous transluminal angioplasty or bypass grafts may be considered in the later stages when irreversible arterial stenosis has occurred and significant ischemic symptoms are observed (15). Angioplasty is preferable when the lesions are amenable to catheter-based therapy. However, percutaneous intervention is less likely to be successful when stenoses or occlusions affect the major portions of an artery or if the artery is heavily scarred. Continued inflammation in a treated segment may result in restenosis following angioplasty with or without stenting; restenosis is less likely to occur after a bypass grafting than after angioplasty, when performed after initiation of treatment, or if revascularization is followed by anti-inflammatory therapy (16).

\section{Conclusions}

Pheochromocytoma is known to be associated with vascular abnormalities. Although cases of renal artery stenosis and renal artery aneurysm have been described previously(17), we found an uncommon phenomenon 
of pheochromocytoma associated with aortoarteritis. Aortoarteritis may represent a form of catecholamineinduced vasculitis.

\section{Acknowledgments}

All the authors would extend their heartfelt thanks to Dr Jagadeesh Tangudu, M Tech, MS, PhD and Sowmya Jammula, M Tech for their immense and selfless contribution towards manuscript preparation, language editing and final approval of text.

\section{Financial Disclosure}

None declared.

\section{Funding/Support}

None declared.

\section{References}

1. Mannelli M, Ianni L, Cilotti A, Conti A. Pheochromocytoma in Italy: a multicentric retrospective study. Eur J Endocrinol. 1999;141(6):619-24.

2. Sasaki A, Yumita S, Kimura S, Miura Y, Yoshinaga K. Immunoreactive corticotropin-releasing hormone, growth hormonereleasing hormone, somatostatin, and peptide histidine methionine are present in adrenal pheochromocytomas, but not in extra-adrenal pheochromocytoma. J Clin Endocrinol Metab. 1990;70(4):996-9.

3. Lenders JW, Pacak K, Walther MM, Linehan WM, Mannelli M, Friberg P, et al. Biochemical diagnosis of pheochromocytoma: which test is best? JAMA. 2002;287(11):1427-34

4. Szolar DH, Korobkin M, Reittner P, Berghold A, Bauernhofer T, Trummer H, et al. Adrenocortical carcinomas and adrenal pheochromocytomas: mass and enhancement loss evaluation at delayed contrast-enhanced CT. Radiology. 2005;234(2):479-85.

5. Plouin PF, Chatellier G, Fofol I, Corvol P. Tumor recurrence and hypertension persistence after successful pheochromocytoma operation. Hypertension. 1997;29(5):1133-9.

6. Lande A, Bard R, Bole P, Guarnaccia M. Aortic arch syndrome (Takayasu's arteritis). Arteriographic and surgical considerations.J Cardiovasc Surg (Torino). 1978;19(5):507-13.

7. Ishikawa K. Patterns of symptoms and prognosis in occlusive thromboaortopathy (Takayasu's disease). J Am Coll Cardiol. 1986;8(5):1041-6.

8. Sekiguchi M, Suzuki J. An overview on Takayasu arteritis. Heart Vessels Suppl. 1992;7:6-10.

9. Kerr GS, Hallahan CW, Giordano J, Leavitt RY, Fauci AS, Rottem M, et al. Takayasu arteritis. Ann Intern Med.1994;120(11):919-29.

10. Chopra P, Datta RK, Dasgupta A, Bhargava S. Immunological studies in aortoarteritis. Indian J Med Res. 1982;76:436-43.

11. Kerr GS. Takayasu's arteritis. Rheum Dis Clin North Am. 1995;21(4):1041-58.

12. Ishikawa K. Effects of prednisolone therapy on arterial angiographic features in Takayasu's disease. Am J Cardiol. 1991;68(4):410-3.

13. Sueyoshi E, Sakamoto I, Hayashi K. Aortic aneurysms in patients with Takayasu's arteritis: CT evaluation. Am J Roentgenol. 2000;175(6):1727-33.

14. Morales E, Pineda C, Martinez-Lavin M. Takayasu's arteritis in children.J Rheumatol.1991;18(7):1081-4.

15. Ishikawa K, Maetani S. Long-term outcome for 120 Japanese patients with Takayasu's disease. Clinical and statistical analyses of related prognostic factors. Circulation. 1994;90(4):1855-60.

16. Liang P, Tan-Ong M, Hoffman GS. Takayasu's arteritis: vascular interventions and outcomes. J Rheumatol. 2004;31(1):102-6.

17. Gill IS, Meraney AM, Bravo EL, Novick AC. Pheochromocytoma coexisting with renal artery lesions. JUrol. 2000;164(2):296-301. 